\title{
Digital Marketing and Creative Economy Theory in Economic Development during the
} Pandemic

\author{
Hsu Yu Shin ${ }^{1}$, May Shun Mynt ${ }^{1}$ \\ ${ }^{1}$ Department of Economics, Dagon University, Myanmar \\ Received: March 14, 2021 \\ Revised: April 8, 2021 \\ Accepted: April 28, 2021
}

\begin{abstract}
Changes in the world require a company to make innovations that are necessary in order to survive the onslaught of other companies' innovations, especially similar companies. a new economic concept that focuses on information and creativity that relies on creative ideas and knowledge from human resources for the main production factors. Creative economynowadays it is increasingly being carried out by the people, especially the younger generation in country because they feel this is a profession that is suitable to be done. Information technology is also needed in the distribution, promotion and sales transaction processes so that the process runs more effectively and efficiently. The potential for the development of this industry is due to several factors, namely the development of information technology as the main factor develops rapidly, access to information centers via the internet is much easier, the social innovation process runs smoothly, each region has a unique local cultural potential and the openness of society to modern culture, there are sources of knowledge such as many campuses that are a source of quality human resources, have high creativity and innovation.
\end{abstract}

Keywords: Digital Marketing, Creative Economy \& Information Technology

\section{Introduction}

The new era of digital marketing has entered the practice of modern society. New markets and new producers have been created using the internet. The use of the internet has made the network of the world community united in what is called a global village. With increasingly broad and global users covering various nations around the world, every society has become a market object for producers as well as a market participant itself. The online marketing strategy has now been recognized as a necessity, because the online strategy connects to various market segments in various cities, both nationally, regionally and internationally. World changes require a company to make innovations necessary to survive the onslaught of other companies' innovations.

Creative economy is a new economic concept that produces its products through the optimization of creative ideas, individual talents, skills, and innovation. Creative Economy has begun to develop into the backbone of the economy in the country in line with the declining contribution of the oil and gas sector to the country's economy. Creative Economy is able to become a source of growth and new strength for a sustainable national economy because ideas, creative power and innovation are renewable and unlimited resources that never stop to always provide added value to the products produced. The driving force of the creative economy is the creative industry. Economically, the role of the creative industry can be seen from two perspectives, namely the contribution to national income and employment

\section{Digital Marketing Concepts and Creative Economy Theory}

The creative economy is a new economic concept that focuses on information and creativity that relies on creative ideas and knowledge from human resources for the main production 
factors. Creative economy nowadays it is increasingly being carried out by the people, especially the younger generation in the state because they feel this is a profession that is suitable to be done. Even though it is very popular, the creative economy has challenges in this time of the Covid-19 pandemic. Lots of SMEs engaged in this field were forced to go out of business because they were unable to survive the recession during the Covid-19 pandemic. There are many reasons why during the Covid-19 pandemic so many SMEs could not survive operating. One of the reasons is the declining purchasing power of the people, which led to a recession. The decline in people's purchasing power is related to the implementation of a work from home system and physical distancing. Plus, the Covid-19 pandemic is not only happening in the country, but also throughout the world.

\section{Digital Creative Industry}

In the 4.0 industrial revolution, there was a combination of automatic and cyber technology so that in business activities there was automation and data exchange (automation and data exchange). As it is known, in the 4.0 industrial revolution, many companies have implemented the concept of digitization / automation in every operational process. The development of digital technology has had a significant impact on the creative economy sector in the country. The impact of the use of digital technology can already be felt in various sub-sectors such as design, music, fine arts and other sub-sectors (Putra, CN, 2018). In connection with these developments, the opportunities for the digital creative industry are getting bigger. The digital creative industry is a creative industry that combines elements of creativity and the use of digital technology in its processes and end products. In the chain of creation and production, technology is needed to acquire, disseminate and exchange information and enrich creative ideas. Information technology is needed during the production process through the use of the internet in the search for new designs. Information technology is also needed in the distribution, promotion and sales transaction processes so that the process runs more effectively and efficiently. The potential for the development of this industry is due to several factors, namely: the development of information technology as the main factor develops rapidly, access to information centers via the internet is much easier, the social innovation process is running smoothly, Each region has a unique local cultural potential and the openness of society to modern culture, there are sources of knowledge such as many campuses that are a source of quality human resources, have high creativity and innovation. The combination of the various factors above results in the meeting of aesthetic and technological elements that produce a distinctive digital creative industry.

\section{Economic Development during the Pandemic}

The role of digital media, which is used for the various needs of everyone in the digital era, is currently growing quite large, especially digital marketing, which is used by companies or personal businesses in the process of marketing industrial products, especially the creative industry. The use of digital media for small-scale creative industry players is still relatively small, so it needs education on the use of digital media whose function is not only a life style but can further be used as a main business support, especially as an online marketing medium.

Currently the industrial world positions itself as one of the economic driving factors that play an important role in the progress of a country's economy (Gilpin, 2018; Heeks, 2008). To advance the country's economy, of course industry must develop and become the main economic activity in a country. As long as a country is still dependent on the results of the agricultural sector or the primary sector, the country can be said to be underdeveloped. Economic development is very important for developing countries which are still struggling because they only depend on one industrial sector, namely agriculture or mining (Szirmai, 2015; Shihab, 2001; Mutti et al., 2012). Therefore, it takes a process, an effort, and an 
improvement in the quality of life as an important element that needs to be considered in relation to a development. The roles of other industries really need to be increased so that economic development can take place quickly. Industrial sectors such as automotive, energy and others must be fully supported by the government. The demand for a more efficient economy led to a greater need for innovation so that the concept of a creative economy was developed to answer these demands. Creative economy is an economic concept that relies on individual creativity in optimizing their competitiveness (Dubina et al., 2012; Hearn, \& Bridgstock, 2010; Sok \& O'Cass, 2015; Menger, 2014). The basic foundation of this creative economy concept is where science and technology are the main inputs in driving economic development and creating good economic growth. The creative economy is driven by an industrial sector called the creative industry.

The creative industry, in today's digital era, has a very important role. The creative economy industry was recorded to have developed positively with a growth of 5.6 percent between 20102013. This industry contributes 7.1 percent of GDP and manages to absorb around 12 million workers, making it one of the mainstay areas to boost people's income and play a strategic role in fighting unemployment and poverty. Meanwhile, in 2016 GDP data for the creative economy industry reached 922.58 billion USD with a national GDP contribution value of $7.44 \%$ or an increase from the previous year of 852.56 billion USD or $7.38 \%$ of national GDP. This figure is also accompanied by the rapid growth rate of $4.95 \%$ in 2016 compared to the previous year of around $4.41 \%$.

In today's digital era, in introducing the results of the creative industry, each group or individual certainly requires media so that their work can be widely known and marketed in order to get maximum results. Therefore, the role of a media plays a very important role in accommodating all the creations of each society so that they can be widely marketed and sold and will be able to continue to carry out their creative industry activities. The purpose of this paper aims to describe the role of digital media as a means of product marketing and media administration in the creative industry.

Marketing is an organizational function and a set of processes for creating, communicating and managing customer relationships in a way that benefits the organization and its stakeholders. Thus, the marketing function is intended to provide understanding to consumers regarding the products and services being marketed or offered. In this sense, marketing is the most fundamental activity in marketing products and services to companies.

Digital Marketing Currently, information technology has entered the main market and is being developed as a new wave technology. New wave technology is a technology that enables connectivity and interactivity between individuals and groups. Digital marketing is a marketing practice that applies "digital distribution" channels to reach consumers in an effective, personal and cost effective manner. Marketing activities are carried out intensively using computer media, both through product offerings, payment and delivery. Marketing Marketing strategy is a form of a company's plan in the marketing field to obtain optimal results. The scope of the marketing strategy is quite broad, including strategies to face competition, product strategies, pricing strategies, place strategies, and promotional strategies. Marketing strategy is a fundamental tool that is planned to achieve company goals by developing sustainable competitiveness through the entered market. So, marketing strategy is a dynamic and innovative process of corporate planning in marketing and introducing products and services offered to consumers to achieve certain goals with all the risks involved. Either through traditional and modern methods such as digital marketing. Marketing strategy is a dynamic and innovative process of corporate planning in marketing and introducing products and services offered to consumers to achieve certain goals with all the risks involved. Either through

Copyright @ $\odot 2021$, Journal of Asian Multicultural Research for Economy and Management Study, 
traditional and modern methods such as digital marketing. Marketing strategy is a dynamic and innovative process of corporate planning in marketing and introducing products and services offered to consumers to achieve certain goals with all the risks involved. Either through traditional and modern methods such as digital marketing.

Innovations in Marketing Social and cultural changes change the value system, lifestyle (life style), modes of production and consumption and other changes (Shove, 2004; Shaw \& Williams, 2004; Geels, 2004; Kozinets et al., 2008; Southerton et al., 2004). Every change always starts from an idea that moves evolutionary and even revolutionary. New innovations in technology are always accompanied by innovations in other fields, including in the field of marketing. Therefore, conventional methods will always be victims and will subsequently collapse. This is what Christensen quoted again by Rheinald Kasali as disruption or attack. Disruption or "attacks" are new ways for people or companies to find innovations in the form of ideas or technology. These are new methods or inventions that will shake up or overthrow the entire old system in new ways. Disruption can threaten incumbents who are already established and are in the pyramid of success by newcomers. Disruption replaces old, allphysical, technology with digital technology that produces something completely new and more efficient, more relevant, and more precise. In this context, commercial companies and / or institutions (whether companies, individuals, or government agencies are required to always innovate, reshape ways of doing business with new, more innovative ways. Disruption replaces old, all-physical, technology with digital technology that produces something completely new and more efficient, more relevant, and more precise. In this context, commercial companies and / or institutions (whether companies, individuals, or government agencies are required to always innovate, reshape ways of doing business with new, more innovative ways. Disruption replaces old, all-physical, technology with digital technology that produces something completely new and more efficient, more relevant, and more precise. In this context, commercial companies and / or institutions (whether companies, individuals, or government agencies are required to always innovate, reshape ways of doing business with new, more innovative ways.

Marketing Strategy There are two words in "marketing strategy", namely the word strategy and the word marketing. The definition of strategy according to Glueck is quoted again in a constant / continuous and adaptive response to outside opportunities and threats as well as internal strengths and weaknesses that can affect the company. Meanwhile, the meaning of marketing is a social process through which individuals and groups get what they need and want. From the explanation above, marketing strategy is a necessary process and the methods and strategies must be continuously updated in accordance with existing social demands. Without appropriate and effective adjustment to new environments, it will be disrupted by other companies, especially those with similar production activities.

\section{Development of the Creative Economy during the Pandemic}

The internet is a basic requirement in the milleneal era like today. There isn't a single job that doesn't need the internet. Internet facilitates all aspects of life from entertainment education, information, public service, knowledge, advertising, investment, interaction or communication, as well as business and selling. Internet can also be enjoyed by all groups, even though they have to sacrifice credit or quota. The existence of the internet is expected to be a supporting and strengthening instrument for creative economy actors and SMEs in developing their business and marketing their sales. Many companies have gone out of business because they cannot keep up with the times.

One of the reasons for the decline of companies in business competition is that they do not expand their market in cyberspace. This is in line with the popular message by Jack Ma, one

Copyright (C 2021, Journal of Asian Multicultural Research for Economy and Management Study, 
of the richest people in the world from China, who advised that only businesses that keep up with the times and technology can last forever. Business activities in the country are largely dominated by the community through the framework of the Creative Economy (hereinafter referred to as Creative Economy) and Micro, Small and Medium Enterprises (hereinafter referred to as MSMEs). The choice of this frame is due to its simple and affordable concept, especially for the middle to lower class society. Even so, Creative Economy and MSME players must also keep up with the times so that they are not inferior to large companies and are able to compete in the market tightly and competitively. For this reason, they must adapt to digital existence using internet media and cyberspace or digital. Community empowerment through science and technology digitizing Village MSMEs is very important to do in the current information age. With more and more small and medium enterprises engaged in the digital economy through broadband, e-commerce, social media, cloud and mobile platforms, SMEs can grow faster in terms of income and employment, and become more innovative and more competitive to face. ASEAN Economic Community.

Digitalization is not only economic or business related. Digitalization must be protected with other instruments so that the business conduct of the perpetrators is as expected by getting the maximum profit and minimizing the risk, namely material or immaterial losses. This digitization is a means that has been facilitated by the State through the ratification of several Legislative Regulations. Business people have started to use information and telecommunications technology to carry out and support their business activities. The movement and changes in the way of doing business that is increasingly fast towards digitalization are forcing business people to adapt to these changes. For large companies, changes in business patterns that lead to the digitization process do not experience too many obstacles due to the characteristics of large companies that have good enough resources. However, for MSMEs this digitization process will require a lot of preparation.

\section{Conclusion}

Online digital marketing through social media such as Facebook, diagrams, and other internet networks that are connected to a wider reach of consumers, an online media sales marketplace that can be accessed globally. The implementation of digital marketing that is carried out can increase sales. This happens because consumers are broader, closer, can check the quality and reputation of the product, and can make transactions online. This will also be more effective due to the conditions of the Covid-19 pandemic which limit all the space for the community to move. With digital marketing, it makes it easier for people to make transactions.

\section{References}

Dubina, I. N., Carayannis, E. G., \& Campbell, D. F. (2012). Creativity economy and a crisis of the economy? Coevolution of knowledge, innovation, and creativity, and of the knowledge economy and knowledge society. Journal of the Knowledge Economy, 3(1), 1-24.

Geels, F. W. (2004). From sectoral systems of innovation to socio-technical systems: Insights about dynamics and change from sociology and institutional theory. Research policy, 33(6-7), 897-920.

Gilpin, R. (2018). The challenge of global capitalism: The world economy in the 21st century. Princeton University Press.

Hearn, G., \& Bridgstock, R. (2010). Education for the Creative Economy: Innovation, Transdisciplinarity. Education in the creative economy: Knowledge and learning in the age of innovation, 93. 
Heeks, R. (2008). Current Analysis and Future Research Agenda on'Gold Farming': RealWorld Production in Developing Countries for the Virtual Economies of Online Games. Development informatics working paper, (32).

Kozinets, R. V., Hemetsberger, A., \& Schau, H. J. (2008). The wisdom of consumer crowds: Collective innovation in the age of networked marketing. Journal of macromarketing, 28(4), 339-354.

Menger, P. M. (2014). The economics of creativity. Harvard University Press.

Mutti, D., Yakovleva, N., Vazquez-Brust, D., \& Di Marco, M. H. (2012). Corporate social responsibility in the mining industry: Perspectives from stakeholder groups in Argentina. Resources Policy, 37(2), 212-222.

Shaw, G., \& Williams, A. (2004). From lifestyle consumption to lifestyle production: Changing patterns of tourism entrepreneurship. Small firms in tourism, 99-114.

Shihab, M. (2001). Economic development in the UAE. United Arab Emirates: a new perspective, 249-259.

Shove, E. (2004). Changing human behaviour and lifestyle: a challenge for sustainable consumption. The ecological economics of consumption, 111-131.

Sok, P., \& O'Cass, A. (2015). Examining the new product innovation-performance relationship: Optimizing the role of individual-level creativity and attention-todetail. Industrial Marketing Management, 47, 156-165.

Southerton, D., Warde, A., \& Hand, M. (2004). The limited autonomy of the consumer: implications for sustainable consumption. Sustainable consumption: The implications of changing infrastructures of provision, 32-48.

Szirmai, A. (2015). Socio-economic development. Cambridge University Press. 